\title{
Three Case Reports with Inoperable Mesenteric Desmoid Tumors
}

\section{Cerrahi Rezeksiyonun Mümkün Olmadığı Mezenterik Desmoid Tümörlü Üç Olgu}

\author{
Umut Varol ${ }^{1}$, Nagihan Akkaş², Utku Oflazoğlü ${ }^{1}$, Tarık Salman ${ }^{1}$, Yaşar Yıldız ${ }^{1}$, Ahmet \\ Alacacıoğlu ${ }^{1}$, Halil Taşkaynatan ${ }^{1}$, Yüksel Küçükzeybek ${ }^{1}$, Mustafa Oktay Tarhan ${ }^{3}$
}

\author{
'İzmir Katip Çelebi Üniversitesi Atatürk Eğitim ve Araştırma Hastanesi, Tıbbi Onkoloji Kliniği, İzmir \\ ${ }^{2}$ İzmir Katip Çelebi Üniversitesi Atatürk Eğitim ve Araştırma Hastanesi, İç hastalıkları Kliniği, İzmir \\ ${ }^{3}$ İzmir Dokuz Eylül Üniversitesi Onkoloji Enstitüsü, İzmir
}

Dergiye Ulaşma Tarihi: 03.08.2018 Dergiye Kabul Tarihi: 20.12.2018 Doi: 10.5505/aot.2019.07078

\section{ÖZET}

Desmoid tümörler yavaş büyüyen ve lokal olarak agresif fibroblastik tümörlerdir. Primer tedaviyi oluşturan cerrahi rezeksiyon sonrası bile lokal rekürrens eğilimi gösterirler. Bu tümörlerin komşu hayati organları invazyonu ciddi morbiditeye neden olabilir ve özellikle ailevi adenomatöz polipozisi olan hastalarda intraabdominal desmoidlerin ortaya çıkması ölümcül sonuçlar doğurabilir. Rezeke edilemeyen, kabul edilemez morbidite olmadan rezeksiyonun mümkün olmadığı ve yeterli lokal terapiye rağmen birçok kez lokal yineleme gösteren hastalarda sistemik tedavi endikedir. Sistemik tedavi seçenekleri sitotoksik kemoterapi, hormonal terapi, nonsteroidal anti-inflamatuar ilaçlar ve hedefleyici ilaçlardır. Tedavinin seçimi, klinik durumun aciliyetine bağlıdır. Bu makalemizde farklı klinik seyir gösteren mezenterik desmoid tümör tanılı üç olgumuzu sunmayı amaçladık.

Anahtar Kelimeler: Desmoid tümör, agressif fibromatozis, olgu sunumu

ABSTRACT
Desmoid tumors are slowly progressing and locally aggressive fibroblastic tumors. Even after primary surgical resection the probability of local recurrence is high. The invasion of these tumors to near vital organs and tissues may produce serious morbidity and especially occurrence of intra-abdominal desmoids tumors in familial adenomatous polyposis may cause mortality. Systemic treatment is necessary if the tumor is inoperable or morbidity is inevitable after radical resection of tumor and there are many local recurrences even after adequate local treatments. Systemic treatment options are cytotoxic chemotherapy, hormonal therapy, nonsteroidal antiinflammatory drugs and targeted treatments. The choice of treatment depends on the symptoms of disease. In this case report we aimed to present three mesenteric desmoid tumor patients with different clinical progress.

Keywords: Desmoid tumor, agressive fibromatosis, case report

\section{GİRIS}

Desmoid tümörler (agressif fibromatozis) yavaş büyüyen, bölgesel olarak büyüme eğilimi gösteren ve metastaz yapma yeteneğinden yoksun olan tümörlerdir (1). Bu nedenle cerrahi ve radyaterapi kullanılarak lokal kontrolü sağlamak geleneksel olarak bu tümörlerin tedavisinin ana dayanağ 1 olmuştur (2-4). Çoğu desmoid tümör, sporadik olarak ortaya çıkmaktadır; buna karşın, \%5-15 oranında ailesel adenomatöz polipozisde (FAP) görülebilmektedir (5-7). FAP, kromozom 5q21-q22 üzerinde bulunan APC (adenomatous polyposis coli) genindeki mutasyonlardan kaynaklanan ve profilaktik 
kolektominin giderek artan kullanımı nedeniyle desmoid tümörlerin morbidite ve mortalitenin önemli bir nedeni haline geldiği bir hastalıktır (8-11). FAP'li bir hastada desmoid tümör gelişme riski, genel nüfustan 852 kat daha fazladır $(11,14)$ ve bu hastalarda ekstremite desmoidleri de oluşabilmesine rağmen, çoğunda abdominal tümörler (intraabdominal veya karın duvarı) gelişmektedir (14-17).

Komplet rezeksiyon sonrasinda bile nüks oranı yüksek olduğu için rezeke edilemeyen, yeterli lokal tedaviye rağmen nükslerle seyreden ve lokal tedavi seçeneklerinin belirgin morbidite yaratacağ semptomatik hastalıklarda sistemik tedavi endikasyonu vardır (18-19). Sistemik tedavi seçenekleri olarak sitotoksik kemoterapi (Doksorubisin, vinka alkaloidlerin ve metotreksat), hormonal terapi (Tamoksifen, megestrol, progesteron ve goserelin), nonsteroidal anti-inflamatuvar ilaçlar (sulindak), hedefleyici tedaviler (imatinib, sorafenib, pazopanib) ve interferon gösterilebilir (20-29). Ajan seçimi, klinik durumun aciliyetine bağlıdır. Kombine kemoterapi gibi agresif tedavi seçenekleri yaşam veya fonksiyon tehdidi yaklaşan hastalar için saklanmalı, sistemik tedaviye uygun diğer hastalar ise hormonal terapi, antiinflamatuvar ilaçlar veya imatinib gibi daha az toksik yaklaşımlarla yönetilmelidir. $\mathrm{Bu}$ makalede tıbbi onkoloji polikliniğinimizde mezenterik desmoid tümör tanısı ile takip ve tedavileri yapılan, ve ilk sıra başlanan tamoksifen tedavisine farklı yanıtların alındığı 3 vakayı sunmayı amaçladık.

\section{OLGU SUNUMU}

Olgu 1: Karında şişlik şikayeti ile başvuran 27 yaşındaki kadın hastanın ilk poliklinik başvurusunda çekilen batın bilgisayarlı tomografisinde (BT) mezenterik bölgede ve anterior karın duvarında yaklaşık $15 \mathrm{~cm}$ çapında ölçülen birleşme eğiliminde olan birden çok kitle görülmüş ve bu kitleler desmoid tümör olarak raporlanmıştır. Batın içi mezenkimal tümörden alınan biyopsi materyalinin morfolojik ve immünohistokimyasal (IHK) bulguları desmoid tümör lehine gelmiştir. Hastada yapılan genetik incelemede, APC: p.N1546K fs19 Heterozigot mutasyonu saptanmıştır. Genel cerrahi tarafinca operasyona uygun olarak kabul edilmeyen hastaya radyasyon onkolojisi radyoterapiyi olası toksisitelerden dolayı uygun görmemiştir. Hastaya Haziran 2017 tarihinde tamoksifen $40 \mathrm{mg} /$ gün tedavisi başlanmıştır. Üç ay sonra çekilen kontrol batın BT'sinde lezyon boyutlarında artış $(25 \times 19 \mathrm{~cm})$ gözlenmiş ve hasta tamoksifen tedavisi altında progesif kabul edilmiştir. Hastanın klinik ve radyolojik ilerlemesi hızlı seyrettiğinden dolayı hastaya doksorubisin kemoterapisi planlanmış ve toplam 4 kür kemoterapi verilmiştir. Bir ay sonra çekilen kontrol BT'sinde kitle boyutlarında değişiklik gözlenmemiş ve stabil olarak kabul edilmiştir. Hastada tedavi süresince ilaca bağlı hayatı tehdit edici herhangi bir yan etki gelişmemiş ve tedaviyi tolere edebilmiştir. Hasta aylık tıbbi onkoloji poliklinik takiplerine devam etmektedir.

Olgu 2: Karında ele gelen kitle nedeni ile genel cerrahi polikliniğine başvuran 28 yaşındaki kadın hastadan alınan biyopsi sonucu ile mezenterik desmoid tümör tanıs1 konmuştur. Hasta cerrahi tarafindan irrezekatabl olarak değerlendirilmiş ve hastaya Ekim 2013 tarihinde tamoksifen 40mg/gün tedavisi başlanmıştır. Hastanın 6 ay sonra çekilen kontrol batın BT'sinde regresyon gözlenmiştir ve hasta tamoksifen tedavisi altında parsiyel yanıtlı kabul edilmiştir. Alınan yanıta rağmen cerrahi rezeksiyonu mümkün olmayan hastanın altı aylık aralıklarla çekilen görüntülemelerinde lezyon boyutlarında büyüme gözlenmemiştir. Hasta halen tamoksifen tedavisi almakta olup tıbbi onkoloji polikliniğinde kontrollerine devam etmektedir.

Olgu 3: FAP tanisı nedeniyle profilaktik total kolektomi ve ileoanal poş cerrahisi öyküsü olan 32 yaşındaki kadın hastanın çekilen kontrol batın BT'sinde mezenterik yağ planlarını hemen tümüyle infiltre eden, sınırları birbirlerinden net olarak ayrımlanamayan diffüz infiltratif-nodüler yumuşak doku dansiteleri saptanmıştır. Mezenterik yumuşak doku infiltrasyonunun öncelikle desmoid tümör infiltrasyonu ile uyumlu olabileceği düşünülmüştür. Hastaya Temmuz 2017 tarihinde alınan biyopsi sonucu mezenterik desmoid tümör tanısı konmuştur. Belirgin şikayeti olmayan hastaya tamoksifen 
40mg/gün tedavisi başlanmıştır. Çekilen Kasım 2017 tarihli batın BT'sinde ilerleme izlemeyen ve tamoksifen tedavisi ile radyolojik ve klinik olarak stabil olarak kabul edilen hastanın tıbbi onkoloji polikliniğinde mevcut tedavisine devam edilmektedir.
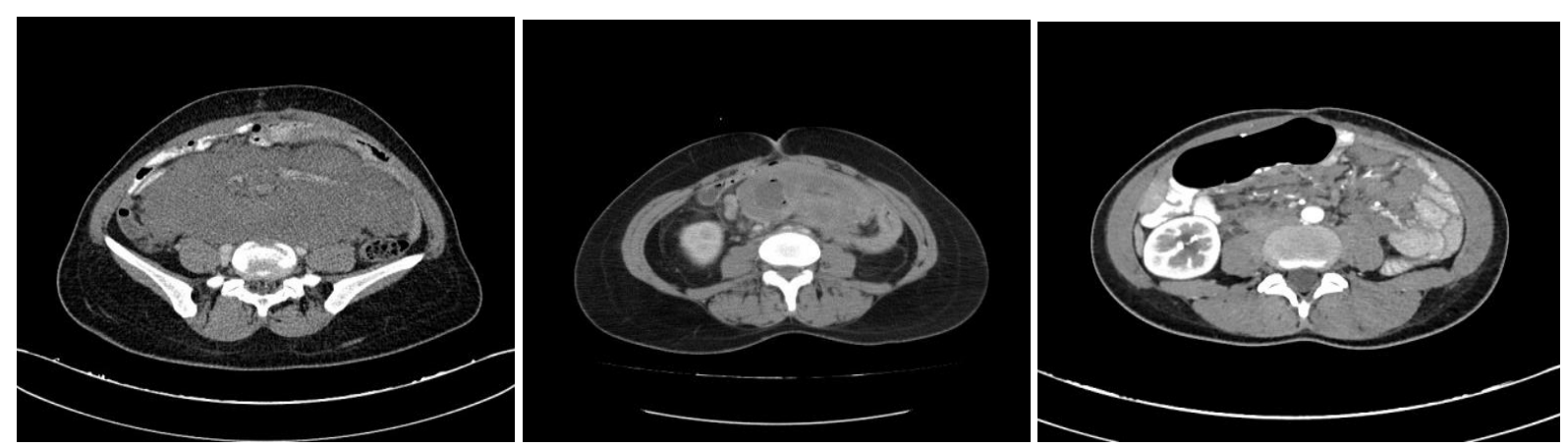

Figür 1 a,b,c. Sırasıyla olgu 1,2 ve 3’te mezenterik desmoid tümörlerin bilgisayarlı tomografi görüntüleri

\section{TARTIŞMA}

Çoğu sporadik agressif fibromatoz vakası ya APC ya da beta-katenin genlerinde (CTNNB1 geni) bir somatik mutasyon içerir (30). CTNNB1 gen mutasyonlar1, sporadik desmoid tümörlerin yaklaşık yüzde 85'ine neden olmaktadır ve sporadik desmoid tümörlerde yüksek rekürrens riski ile ilişkilidir. APC gen mutasyonları ailevi adenomatöz polipoz ile ilişkili desmoid tümörlerin yanı sıra sporadik desmoid tümörlerin \%10-15'ine neden olabilmektedir (31). Her iki gen, hücrelerin büyümesini ve proliferasyonunu kontrol eden hücre sinyal yolağına ve hücrelerin farklılaşma fonksiyonlarının gerçekleştirildiği sürece dahil olur. $(32,33)$. APC geninden üretilen protein, hücredeki $\beta$-katenin seviyelerini düzenlemeye yardımc duyulmadığında, APC proteini parçaya bağlanır ve bu proteinin parçalanmasına işaret eder. CTNNB1 veya APC gen mutasyonları sonucu $\beta$-katenin parçalanamaz ve bunun yerine hücrelerde birikir. Fazla miktardaki beta-katenin kontrolsüz büyümeyi ve bölünmeyi teşvik eder ve desmoid tümörlerin oluşumuna neden olur (34). Plazminojen aktivatör inhibitörü-1 (PAI-1) agresif fibromatozisde yüksek düzeyde eksprese edilmektedir. PAI-1'in tümör büyümesini inhibe edebilen hücresel etkileri olmasına rağmen, agresif fibromatozda tümör büyümesini arttırıcı rolü bulunmaktadır. $\beta$ kateninin, PAI-1'i düzenleme kabiliyeti araştırılmış ve PAI-1'in dolaylı bir hedef olduğu bulunmuştur. PAI-1 promotorundaki 4G polimorfizmi ile ailesel adenomatöz polipoz hastalarında agresif fibromatoz gelişimi arasında bir ilişki bulunmuştur (35).

Desmoid tümörlerin tedavi yaklaşımı multidisiplinerdir. Metastaz nadir görüldüğü için geniş cerrahi rezeksiyon veya radyoterapiye yanit verebilirler. Bununla birlikte FAP'l1 hastalar veya lokal tedaviye yanitsiz hastalarda sistemik tedavi gerekebilir $(2,30)$. Konservatif ve cerrahi tedavinin karşılaştırıldığı bir çalışmada PFS sırasıyla $\% 49$ ve \% 33 olarak bulunmuştur (36). Asemptomatik ve yavaş seyirli hastalıkta başlangıçta sitotoksik olmayan hormonal tedavi, antiinflamatuvar tedaviler veya imatinib, sorafenib, pazopanib gibi sistemik tedaviler tercih edilmelidir (20-29). Kombine kemoterapi gibi agresif tedavi seçenekleri ise yaşamı tehdit eden hastalığ 1 olan hastalar için saklanmalıdir. Antrasiklin monoterapisi ve haftalık düşük doz metotreksat+vinka alkaloid kombinasyonuna kıyasla, antrasiklin-bazlı kemoterapi kombinasyonu (örn. Doksorubisin + dakarbazin) ile yanıt oranları daha yüksek ve PFS daha iyidir ancak toksisitesi daha fazladır (37). Biz üç vakamıza da başlangıçta asemptomatik olması nedeniyle tamoksifen tedavisi verdik ancak bir vakada hastalığın hızlı ilerlemesi nedeni ile doksorubisin kemoterapisine geçtik.

Desmoid tümörler tipik olarak yavaş büyümektedirler. Sitotoksik tedavi süresi ve 
yanıt değerlendirme ile ilgili bir görüş birliği bulunmamaktadır. Hastalarda 4 hafta içinde semptomatik iyileşme gözlenebilirken uzun süre takip sonunda da yanıt alınabilmektedir $(18,19)$. Ancak bizim bir vakamıda tamoksifen altında semptomlarının artması ve kliniğinin hızla bozulması sebebiyle erken değerlendirme yapılmıştır ve kitlenin hızla büyümesi nedeniyle sitotoksik tedaviye geçilmiştir. $\mathrm{Bu}$ nedenle yanıt değerlendirilmesinde esas alınan hastanın kliniği olmalıdır. Tedavi ve yanıt değerlendirme semptomların ciddiyetine, lezyonların yaygınlığına ve FAP gibi bir sistemik hastalığın varlığına bağlı olarak bireyselleştirilmelidir.

Yapılan multivaryant çalışmalar ile kadın cinsiyet ve aile hikayesi desmoid tümör için bağımsız risk faktörleri olarak belirlenmişlerdir. Sonuç olarak, desmoid tümörlü hastalarda; detaylı bir aile öyküsü, üst ve alt gastrointestinal sistemin endoskopik değerlendirilmesi, APC tam gen dizilimi gibi genetik analizler hayati önem taşımaktadır ve desmoid tümörlü hastaların standart değerlendirmesinin bir parçası olmalıdır. Çünkü bunlar ailevi adenomatöz polipozisin sentinel bulgusu olabilir. Özellikle genç kadın hastalarda mezenterik kökenli kitlelerde nadir görülse de desmoid tümörün akılda bulundurulması ve tetkik sürecinin buna göre yapılması önemlidir.

\section{KAYNAKLAR}

1. Posner MC, Shiu MH, Newsome JL, Hajdu SI, Gaynor JJ, Brennan MF. The desmoid tumor. Not a benign disease. Arch Surg. 1989;124(2):1916.

2. Fiore M, Rimareix F, Mariani L, et al. Desmoidtype fibromatosis: a front-line conservative approach to select patients for surgical treatment. Ann Surg Oncol. 2009;16(9):2587.

3. Ballo MT, Zagars GK, Pollack A, Pisters PW, Pollack RA. Desmoid tumor: prognostic factors and outcome after surgery, radiation therapy, or combined surgery and radiation therapy. J Clin Oncol. 1999;17(1):158.

4. Huang $\mathrm{K}, \mathrm{Fu} \mathrm{H}$, Shi YQ, Zhou Y, Du CY. Prognostic factors for extra-abdominal and abdominal wall desmoids: a 20-year experience at a single institution. J Surg Oncol. 2009;100(7):563-9.

5. Nieuwenhuis $\mathrm{MH}$, Casparie $\mathrm{M}$, Mathus-Vliegen LM, Dekkers OM, Hogendoorn PC, Vasen HF. A nation-wide study comparing sporadic and familial adenomatous polyposis-related desmoid-type fibromatoses, Int J Cancer. 2011;129(1):256-61.

6. Fallen $\mathrm{T}$, Wilson $\mathrm{M}$, Morlan $\mathrm{B}$, Lindor NM. Desmoid tumors -- a characterization of patients seen at Mayo Clinic 1976-1999. Fam Cancer. 2006;5(2):191-4.

7. Koskenvuo L, Peltomäki P, Renkonen-Sinisalo L, et al. Desmoid tumor patients carry an elevated risk of familial adenomatous polyposis. J Surg Oncol. 2016;113(2):209-12.

8. Nieuwenhuis $M H$, Lefevre $J H$, Bülow $S$, et al. Family history, surgery, and APC mutation are risk factors for desmoid tumors in familial adenomatous polyposis: an international cohort study. Dis Colon Rectum. 2011;54(10):1229-34.

9. Quintini C, Ward G, Shatnawei A, et al. Mortality of intra-abdominal desmoid tumors in patients with familial adenomatous polyposis: a single center review of 154 patients. Ann Surg. 2012 Mar;255(3):511-6.

10. Church JM. Mucosal ischemia caused by desmoid tumors in patients with familial adenomatous polyposis: report of four cases. Dis Colon Rectum. 1998;41(5):661.

11. Sagar PM, Möslein G, Dozois RR. Management of desmoid tumors in patients after ileal pouch-anal anastomosis for familial adenomatous polyposis. Dis Colon Rectum. 1998;41(11):1350.

12. Penna C, Tiret E, Parc R, et al. Operation and abdominal desmoid tumors in familial adenomatous polyposis. Surg Gynecol Obstet. 1993;177(3):263.

13. Kadmon M, Möslein G, Buhr HJ, Herfarth C. [Desmoid tumors in patients with familial adenomatous polyposis (FAP). Clinical and therapeutic observations from the Heidelberg polyposis register. Chirurg. 1995;66(10):997.

14. Arvanitis ML, Jagelman DG, Fazio VW, Lavery IC, McGannon E. Mortality in patients with familial adenomatous polyposis. Dis Colon Rectum. 1990;33(8):639.

15. Quintini C, Ward G, Shatnawei A, et al. Mortality of intra-abdominal desmoid tumors in patients with familial adenomatous polyposis: a single center review of 154 patients. Ann Surg. 2012;255(3):5116.

16. Gurbuz AK, Giardiello FM, Petersen GM, et al. Desmoid tumours in familial adenomatous polyposis. Gut. 1994;35(3):377.

17. Lynch HT, Fitzgibbons R Jr. Surgery, desmoid tumors, and familial adenomatous polyposis: case report and literature review. Am J Gastroenterol. 1996;91(12):2598.

18. Lev D, Kotilingam $\mathrm{D}$, Wei $\mathrm{C}$, et al. Optimizing treatment of desmoid tumors. J Clin Oncol. 2007;25(13): 1785 .

Adress for correspondence: Umut Varol, İzmir Katip Çelebi Üniversitesi Atatürk Eğitim ve Araştrrma Hastanesi, Tıbbi Onkoloji Kliniği, İzmir Karabağlar, İzmir - Türkiye e-mail:varolumut@yahoo.com

Available at www.actaoncologicaturcica.con

Copyright $\odot$ Ankara Onkoloji Hastanesi 
19. Meazza C, Bisogno G, Gronchi A, et al. Aggressive fibromatosis in children and adolescents: the Italian experience. Cancer. 2010;116(1):233.

20. Azzarelli A, Gronchi A, Bertulli R, et al. Low-dose chemotherapy with methotrexate and vinblastine for patients with advanced aggressive fibromatosis. Cancer. 2001;92(5):1259.

21. Garbay D, Le Cesne A, Penel N, et al. Chemotherapy in patients with desmoid tumors: a study from the French Sarcoma Group (FSG). Ann Oncol. 2012;23(1):182-6.

22. Hansmann A, Adolph $\mathrm{C}$, Vogel $\mathrm{T}$, Unger $\mathrm{A}$, Moeslein G. High-dose tamoxifen and sulindac as first-line treatment for desmoid tumors. Cancer. 2004;100(3):612.

23. Lackner H, Urban C, Kerbl R, Schwinger W, Beham A. Noncytotoxic drug therapy in children with unresectable desmoid tumors. Cancer. 1997;80(2):334-40.

24. Fiore M, Colombo C, Radaelli S, et al. Hormonal manipulation with toremifene in sporadic desmoidtype fibromatosis. Eur J Cancer. 2015;51(18):28007.

25. Janinis J, Patriki M, Vini L, Aravantinos G, Whelan JS. The pharmacological treatment of aggressive fibromatosis: a systematic review. Ann Oncol. 2003;14(2):181-90.

26. Chugh R, Wathen JK, Patel SR, et al; Sarcoma Alliance for Research through Collaboration (SARC). Efficacy of imatinib in aggressive fibromatosis: Results of a phase II multicenter Sarcoma Alliance for Research through Collaboration (SARC) trial. Clin Cancer Res. 2010;16(19):4884-91.

27. Gounder MM, Lefkowitz RA, Keohan ML, et al. Activity of Sorafenib against desmoid tumor/deep fibromatosis. Clin Cancer Res. 2011;17(12):408290.

28. Szucs Z, Messiou C, Wong HH, et al. Pazopanib, a promising option for the treatment of aggressive fibromatosis. Anticancer Drugs. 2017;28(4):421426.

29. Leithner A, Schnack B, Katterschafka T, et al. Treatment of extra-abdominal desmoid tumors with interferon-alpha with or without tretinoin. J Surg Oncol. 2000;73(1):21-5.

30. Escobar C, Munker R, Thomas JO, Li BD, Burton GV. Update on desmoid tumors. Ann Oncol. 2012;23(3):562-9.

31. Giarola $M$, Wells $D$, Mondini $P$, et al. Mutations of adenomatous polyposis coli (APC) gene are uncommon in sporadic desmoid tumours. $\mathrm{Br} \mathrm{J}$ Cancer. 1998;78(5):582.

32. Li C, Bapat B, Alman BA. Adenomatous polyposis coli gene mutation alters proliferation through its beta-catenin-regulatory function in aggressive fibromatosis (desmoid tumor). Am J Pathol. 1998;153(3):709.

33. Tejpar S, Nollet F, Li C, et al. Predominance of beta-catenin mutations and beta-catenin dysregulation in sporadic aggressive fibromatosis (desmoid tumor). Oncogene. 1999;18(47):6615.

34. Aitken SJ, Presneau N, Kalimuthu S, et al. Nextgeneration sequencing is highly sensitive for the detection of beta-catenin mutations in desmoid-type fibromatoses. Virchows Arch. 2015;467(2):203-10.

35. Li CF, Wei RY, Baliko F, Bapat B, Alman BA. An association between the $4 \mathrm{G}$ polymorphism in the PAI-1 promoter and the development of aggressive fibromatosis (desmoid tumor) in familial adenomatous polyposis patients. Fam Cancer. 2007;6(1):89-95.

36. Bertagnolli MM, Morgan JA, Fletcher CD, et al. Multimodality treatment of mesenteric desmoid tumours. Eur J Cancer. 2008;44(16):2404.

37. Nieuwenhuis MH, Mathus-Vliegen EM, Baeten $\mathrm{CG}$, et al. Evaluation of management of desmoid tumours associated with familial adenomatous polyposis in Dutch patients. $\mathrm{Br} \mathrm{J}$ Cancer. 2011;104(1):37. 